\section{G250(P) SUPRAVENTRICULAR TACHYCARDIA DUE TO BLUNT CHESTTRAUMA}

1J Haslam, ${ }^{1} \mathrm{M}$ Bird, ${ }^{1} \mathrm{M}$ Cosgrove, ${ }^{2} \mathrm{O}$ Uzun, ${ }^{1} \mathrm{P}$ Vallabhaneni. ${ }^{1}$ Paediatrics, Morriston Hospital, Swansea, UK; ${ }^{2}$ Paediatric Cardiology, University Hospital of Wales, Cardiff, UK

10.1136/archdischild-2018-rcpch.243

Aims Blunt cardiac injury is more prevalent in children and this may cause commotio cordis or ventricular arrhythmias. Commotio cordis is the devastating consequence of otherwise innocent-appearing chest-wall blows, with sudden cardiac death often resulting from projectiles striking the precordium. The spectrum of injuries to the heart includes damage to the great vessels, myocardial rupture or contusion, and valvular disruption. Pericardial effusions, conduction abnormalities and ventricular arrhythmias may also occur.

Methods/results We report a case of atrial arrhythmia in a 7 year old boy following blunt trauma to the chest.This previously healthy boy reported being unwell after he was hit by a football whilst playing. The impact was directly to the left anterior chest wall. A12-lead electrocardiogram (ECG) done in primary care showed supraventricular tachycardia (SVT) at a rate of $225 \mathrm{bpm}$. On arrival to the hospital his heart rate had reverted to normal limits. Twenty-four-hour Holter monitoring was normal, recording brief periods of sinus arrhythmia, infrequent sinus tachycardia of gradual onset and no episodes of SVT or ectopic activity. A transthoracic echocardiogram excluded structural abnormalities of the heart. He was started on Sotalol and is currently doing well with no sequelae from the injury. Final diagnosis of Wolf-Parkinson White syndrome was made following detailed investigations.

Conclusions We hypothesise that the blow elucidated a previously unknown congenital accessory conduction pathway. We would like to raise the awareness of such possibilities amongst children and importance of detailed investigations to detect underlying predisposing pathologies.

\section{G251(P) CARDIAC MURMURS IN NEONATES: REVIEW OF CURRENT LOCAL PRACTICE AND CLINICAL OUTCOMES}

H Rao, A Shenvi. University Hospital of North Midlands, Stoke on Trent, UK

\subsection{6/archdischild-2018-rcpch.244}

Aim To review the result of modifications to regional network guidelines in the management of neonatal heart murmurs.

Background The local trust guidelines for the management of neonatal heart murmurs were formulated by the modification of the South West Midlands Maternity and Newborn Network (SWMMNN) guidelines. The modifications included the following - Babies with murmurs are reviewed again as inpatients at $\geq 24$ hours of age to identify any change, electrocardiography is not done as first line investigation, outpatient review is done within 2 to 3 weeks as opposed to 2 to 6 weeks and referred to neonatal cardiology outpatient clinic if the murmur is persistent.

Methods This was a retrospective review of 3131 babies born between December 2016 and May 2017. Data was obtained from the case notes and electronic records.Babies with antenatally detected congenital heart disease and babies admitted to the neonatal unit for other reasons were excluded.

Results 93 babies (3\%) had murmurs detected at birth. Murmurs resolved in 60 babies $(64.5 \%)$ within 24 hours. Murmurs persisted for more than 24 hours in 33 babies and all these babies were reviewed in neonatal outpatient clinic in 2-3 weeks. The mean waiting time for echocardiography was 15 weeks. 25 babies were discharged $(75 \%)$ from the clinic after resolution of the murmur. Out of the remaining 8 babies, one baby' s murmur disappeared, one had an innocent murmur, two had congenital heart disease diagnosed (severe pulmonary stenosis with right ventricular hypertrophy and dilatation, moderate pulmonary stenosis) and were transferred to a tertiary centre. Four are awaiting outpatient appointments. Providing written information to general practitioners and parents was found to be inadequate.

Conclusion Review at $\geq 24$ hours of age significantly reduces the need for investigations, outpatient appointments and also decreases parental anxiety. Communication to GPs and parents should be improved with emphasis on when and whom to seek help. A generic letter to GPs and a parent information leaflet were formulated to improve this. There is a need for reduction in the mean waiting time for outpatient echocardiography. This could be achieved by training more paediatricians to develop an expertise in cardiology.

\section{G252(P) HOW RELEVANT IS AN INCIDENTAL FINDING OF ABNORMAL CARDIAC SILHOUETTE ON CHEST X-RAY?}

FRS Scott, JW Walker, PR Ramesh. Paediatric Intensive Care Unit, University Hospitals of North Midlands, Stoke on Trent, UK

\subsection{6/archdischild-2018-rcpch.245}

Aim Abnormal cardiac size and shape on chest X-Ray (CXR) causes anxiety to paediatricians as it could be due to an underlying heart disease. We reviewed the echocardiogram findings of all children who were referred because of an incidental finding of an abnormal cardiac silhouette on CXR. None of these children had any abnormal signs or symptoms of a cardiac condition at the time of referral.

Methods Retrospective analysis of the patients whose data was prospectively collected over a 3 year period (Nov 2014-Oct 2017).

\begin{tabular}{|c|c|c|c|c|}
\hline No & Age & Indication for CXR & Abnormality on CXR & $\begin{array}{l}\text { Echocardiogram } \\
\text { result }\end{array}$ \\
\hline 1. & $7 \mathrm{~m}$ & $\begin{array}{l}\text { Swallowed foreign } \\
\text { body }\end{array}$ & Cardiomegaly & Normal \\
\hline 2. & 1 day & Sepsis & Prominent aortic arch & Normal \\
\hline 3. & $14 \mathrm{y}$ & Cough & ?Scimitar syndrome & Normal \\
\hline 4. & $4 \mathrm{~m}$ & Fever and grunting & ?Dextrocardia & Normal \\
\hline 5. & $9 y$ & Asthma & $\begin{array}{l}\text { Prominent pulmonary } \\
\text { trunk }\end{array}$ & Normal \\
\hline 6. & $4 \mathrm{~m}$ & Chest infection & Cardiomegaly & Normal \\
\hline 7. & $8 \mathrm{~m}$ & Chest infection & Cardiomegaly & Normal \\
\hline 8. & $14 \mathrm{~m}$ & cough & Cardiomegaly & $\begin{array}{l}\text { Small pericardial } \\
\text { effusion }\end{array}$ \\
\hline
\end{tabular}

Results Eight patients were referred for echocardiogram and their details are given below (table 1).

CXR was reported by paediatric radiologists for six children, adult radiologist for one child and consultant paediatrician for one child. CXR was done $(\mathrm{P}) \mathrm{O}$ Anterior (PA) erect in three children, Antero (P)ior (AP) erect in one child and AP supine 